\title{
Cessation Treatment Adherence and Smoking Abstinence in Patients Post-Acute Myocardial Infarction
}

\author{
Short Title: Treatment Adherence and Smoking Abstinence in Patients Post-MI
}

\author{
Sonia M. Grandi, MSc, ${ }^{1}$ Mark J. Eisenberg, MD, MPH, ${ }^{1,2,3}$ Lawrence Joseph, PhD,${ }^{1,4}$ \\ Jennifer O'Loughlin, PhD, ${ }^{5}$ Gilles Paradis, MD MSc, ${ }^{1}$ Kristian B. Filion, $\mathrm{PhD}^{1,2,6}$ \\ ${ }^{1}$ Department of Epidemiology, Biostatistics and Occupational Health, McGill University, \\ Montreal, QC, Canada, \\ ${ }^{2}$ Center for Clinical Epidemiology, Lady Davis Institute, Jewish General Hospital, Montreal, QC, \\ Canada, \\ ${ }^{3}$ Division of Cardiology, Jewish General Hospital, McGill University, Montreal, QC, Canada, \\ ${ }^{4}$ Division of Clinical Epidemiology, McGill University Health Centre, Montreal, QC, Canada, \\ ${ }^{5}$ CRCHUM and the Department of Social and Preventive Medicine, Université de Montréal, \\ Montréal, QC, Canada, \\ ${ }^{6}$ Division of Clinical Epidemiology, McGill University, Montreal, QC, Canada.
}

Word Count: 2,000

Address for Correspondence:

Kristian B. Filion, PhD FAHA

Assistant Professor of Medicine

Division of Clinical Epidemiology

Lady Davis Institute, Jewish General Hospital, McGill University

5750 Cote-des-Neiges, Suite H-416.1

Montreal, Quebec, Canada

H3T 1E2

Telephone: (514) 340-8222 Ext. 8394

Fax: (514) 340-7564

Email: kristian.filion@mcgill.ca 


\section{STRUCTURED ABSTRACT}

Background: Previous trials examining the use of bupropion for smoking cessation therapy postmyocardial infarction (MI) have been inconclusive. To better understand the observed lack of effectiveness of bupropion in this population, we examined abstinence rates by level of adherence across treatment groups.

Methods: We used data from a randomized, double-blind, placebo-controlled trial of bupropion in smokers ( $\mathrm{n}=388$ ) hospitalized with MI to study the association of interest. Patients were classified as being fully adherent if they reported taking 2 pills/day, partially adherent if they reported 0,1 and/or 2 pills/day, and non-adherent if they reported 0 and/or 1 pill/day throughout the 9 -week treatment period. Abstinence was assessed by 7-day biochemically-validated self-report at 4 and 9 weeks and 6 and 12 months.

Results: A total of 156 patients were fully adherent to the study medication (66 bupropion and 90 placebo), 149 were partially adherent (76 and 73, respectively) and 83 were non-adherent (46 and 37, respectively). Regardless of treatment group, patients who were fully or partially adherent reported greater abstinence than non-adherent patients. Among partially adherent patients, bupropion conferred an important benefit at 12 months (\% difference, 13.3, 95\% CI 1.3, 25.3). At 12 months, patients who were fully adherent were more likely to be abstinent compared to those who were non-adherent (adjusted OR 7.6, 95\% CI 3.2, 17.6).

Conclusions: Adherence to study medication, regardless of assigned treatment, is associated with a substantial increase in abstinence. Patients who are motivated to quit smoking should be targeted for smoking cessation treatment post-MI. 


\section{INTRODUCTION}

Although the benefit of smoking cessation on clinical outcomes in myocardial infarction (MI) patients surpasses that of other evidence-based post-MI therapies, ${ }^{1,2}$ more than $50 \%$ of patients relapse within the first year post-MI. ${ }^{3}$ The use of pharmacotherapy, including varenicline, bupropion, and nicotine replacement therapy, doubles abstinence rates in healthy individuals as well as in patients with a history of cardiovascular disease..$^{4-7}$ However, trials investigating bupropion as a smoking cessation therapy in patients with acute cardiovascular disease have been inconclusive. ${ }^{8-10}$ A possible explanation for these discordant findings is that adherence to study medication may be different in this patient population.

Two previous studies examining adherence to smoking cessation therapies and abstinence found that adherence improved the likelihood of remaining abstinent. ${ }^{11,12}$ However, these studies were limited by their small samples, heterogeneous study populations, and lack of assessment of long-term abstinence. In order to investigate this issue, we examined abstinence rates at 12 months by level of adherence to cessation pharmacotherapy in post-MI patients randomly assigned to bupropion or placebo.

\section{METHODS}

Data were available in a multi-center, randomized, double-blind, placebo-controlled trial investigating the efficacy of bupropion for smoking cessation in MI patients $(n=388)$. The full details of the trial have been described elsewhere. ${ }^{10}$ Briefly, inclusion criteria included that the patient smoked a minimum of 10 cigarettes per day, was $\geq 18$ years of age, had suffered an enzymepositive MI, and was motivated to quit. Patients were randomized to bupropion (150 $\mathrm{mg}$ per day) or placebo treatment for 9 weeks and returned for clinic visits at 4 and 9 weeks, and at 6 and 12 months. All patients received motivational support from either a research nurse or a trained smoking 
cessation counselor at baseline and follow-up visits. Patients who died or withdrew during the treatment period $(n=7)$ were excluded from the analysis and those who died during follow-up $(n=8)$ were censored at the time of death.

Adherence was assessed by self-report by telephone calls at weeks 1 and 2 and, in clinical visits at weeks 4 and 9, where a pill count was undertaken in addition to self-report. Adherence was categorized using a summary score based on the total number of pills/day reported at each of the 4 follow-up visits during the 9 -week treatment period. Based on this scoring system, individuals were classified as a either, 1) fully adherent - a total score of 8 , including individuals who reported taking 2 pills/per day at each of the 4 follow-up visits; 2) partially adherent - a summary score of 4-7, including individuals who reported taking a combination of 0,1 , and/or 2 pills/day during the treatment period; 3) non-adherent - total score of $\leq 3$, including individuals who reported a combination of 0 and/or 1 pill/week.

Abstinence was assessed at all clinic visits by self-report and validated by expired carbon monoxide (CO). Smoking abstinence in the current study refers to abstinence from cigarette smoking in the week prior to the follow-up visit. Point prevalence abstinence was defined as reporting no cigarettes smoked in the last 7 days with an expired $\mathrm{CO} \leq 10 \mathrm{ppm}$ at the 4 - and 9-week and 6- and 12-month clinic visits. Patients lost to follow-up during the treatment period were considered to be non-adherent, and patients lost to follow-up at any time during the 12-month follow-up were considered to have returned to smoking.

\section{Data Analysis}

Baseline demographic, smoking, and clinical characteristics are reported as means with standard deviations (SD) or percentages, as appropriate. The association between adherence and abstinence is presented as differences in proportions with corresponding $95 \%$ confidence intervals 
(CI) between treatment and adherence groups. The independent association between adherence to medication and abstinence was assessed using multivariable logistic regression. Covariates were selected based on clinical judgment and substantive knowledge regarding the potential association between adherence and smoking cessation and included age, sex, other smokers at home (yes, no), number of previous quit attempts (0-10), number of cigarettes smoked per day at baseline, the Fagerstrom Tolerance Questionnaire (FTQ) Score at baseline (as a continuous variable), the Beck Depression (BDII) score at baseline (0-13 [no depressive symptomatology], BDII $\geq 14$ [any depressive symptomology], number of years smoked, percutaneous coronary intervention (yes, no), and ST-segment elevation MI (yes, no). Statistical analyses were performed using the SAS statistical software (Version 9.2) and R (Version 3.1.2 http://www.r-project.org/).

\section{RESULTS}

The sample included $388 \mathrm{MI}$ patients. Most participants (83.3\%) were male, and the mean age at baseline was 53.8 years (SD 10.4). Patients had smoked for three decades on average, and they smoked an average of 23 cigarettes per day prior to their MI. A total of 156 patients were fully adherent to the study medication (66 in the bupropion group and 90 in the placebo group), 149 were partially adherent (76 and 73, respectively) and 83 were non-adherent (46 and 37, respectively; Table 1). Non-adherent patients in the bupropion group were more likely to report living with other smokers and to have hypertension compared to the fully and partially adherent group. Non-adherent patients in the placebo group were more likely to have prior history of diabetes mellitus but less likely to have hypertension compared to patients who were partially and fully adherent. Overall, baseline characteristics were similar between treatment and adherence groups.

Approximately $42 \%$ of patients experienced a side effect over the 9 -week treatment period (Table 2). The most common side effects were insomnia (19.7\%) and dry mouth (10.4\%). Among 
patients in the bupropion group, patients who were partially adherent were more likely to report any side effect compared to patients who were non-adherent (between-adherence group difference $=$ $18.6 \%, 95 \%$ CI $1.2 \%, 35.9 \%)$. Patients in the bupropion group who were partially adherent were also more likely to report dry mouth compared to non-adherent patients (between-adherence group difference $=10.8 \%, 95 \% \mathrm{CI} 0.0 \%, 21.5 \%$ ). In the placebo group, a higher proportion of fully and partially adherent patients reported a bad taste in mouth compared to non-adherent patients (between-adherence group difference $=8.9 \%, 95 \%$ CI $3.0 \%, 14.8 \%$ and $6.9 \%, 95 \%$ CI $1.1 \%, 12.6 \%$, respectively). Among patients who discontinued study medication $(\mathrm{n}=123), 10.7 \%$ reported side effects as the primary reason. Among patients who discontinued, $<1.0 \%$ discontinued study medication due to a serious adverse event.

Regardless of treatment group, patients who were fully or partially adherent reported greater abstinence than non-adherent patients (Table 3). The most notable differences were found during the treatment period, but important differences persisted until 12 months. Differences in abstinence between treatment groups were seen for the partially adherent and non-adherent groups at 6 months. This trend was found to persist in the partially adherent group at 12 months. No important differences between the treatment groups among fully adherent patients were noted due to high rates of abstinence in the placebo group. The beta coefficients for the test of interaction between treatment group and adherence were inconclusive due to wide CIs, likely related to the modest sample size (data not shown). However, at 12 months, patients who reported being fully adherent were more likely to be abstinent compared to patients who reported being partially adherent and non-adherent (adjusted odds ratio [OR] 3.5, 95\% CI 2.0, 6.0 and adjusted OR 7.6, 95\% CI 3.2, 17.6, respectively). Although the point estimate suggests increased abstinence among individuals who 
were partially adherent to study medication compared to those who were non-adherent (adjusted OR 2.2, 95\% CI 0.9, 5.3), the wide CI makes it difficult to draw strong conclusions.

\section{DISCUSSION}

This analysis examined abstinence at 12 months and level of adherence to study medication in post-MI patients across treatment groups. We found that regardless of treatment, patients who were fully adherent were more likely to be abstinent at 12 months. Bupropion was efficacious for smoking cessation in patients who were partially adherent to study medication, with no observed benefit among those who were fully adherent or not adherent. Moreover, the lack of effectiveness of bupropion among fully adherent patients suggests that adherence may be a marker for motivation to quit smoking post-MI.

Previous studies in the general population have identified non-adherence to medication as an important predictor of smoking relapse. ${ }^{13}$ Determinants of non-adherence suggested to influence relapse include: 1) newly-acquired medical conditions; 2) occurrence of side effects; and 3) perceived lack of treatment efficacy. ${ }^{13-17}$ Non-adherence to treatment due to side effects may partially explain our findings since approximately $11 \%$ of patients discontinued their medication as a result of side effects. However, whether the side effects reported by patients are a result of the study medication or a combination of other therapies given to post-MI patients is unclear. Moreover, due to the relatively small number of patients, it would be difficult to provide any meaningful conclusions regarding the timing of side effects and subsequent adherence. Despite this, patients who are taking smoking cessation therapies should be carefully monitored in order to reduce the potential for side effects and discontinuation as a result of side effects.

Studies in the general population suggest that adherence to smoking cessation therapy is generally low, particularly among individuals using over-the-counter pharmacotherapies such as 
nicotine replacement therapy. ${ }^{18,19}$ Moreover, adherence may be a proxy for level of motivation to quit. $^{20,21}$ Although a quarter of patients were non-adherent in this study, the proportion was substantially lower than in the general population. ${ }^{15,22}$ This may be a result of the inclusion criteria for the trial, which required that patients be motivated to quit smoking. Alternatively, our study was conducted in patients hospitalized for an MI, a 'teachable moment' during which patients are more likely to adopt lifestyle changes as a result of their recent cardiac event. ${ }^{23}$ A higher level of motivation among post-MI patients may also explain the large differences in abstinence rates at 6 and 12 months between non-adherent and fully adherent patients in both treatment groups.

Successful cessation typically requires multiple attempts. While patients in this trial had smoked three decades on average and had moderate levels of nicotine dependence, the range in number of previous quit attempts was wide $(0-10)$. Patients who have never tried to quit may be less likely to adhere to treatment and more likely to relapse than those with a previous history of unsuccessful attempts. ${ }^{24-26}$ Although we considered the number of previous quit attempts as a candidate variable in our regression models, it ultimately was not an important confounder in our study. Nonetheless, there remains a need to better understand the relationship between the number of previous quit attempts, treatment adherence, and smoking cessation.

Our study has some potential limitations. First, adherence was based primarily on self-report and misclassification is possible. However, it is unlikely that this would be differential across treatment and adherence groups given the double-blind study design, and self-report was supplemented by pill counts during clinic visits. Second, as is conventional in smoking cessation trials, ${ }^{6-8}$ patients lost-to-follow-up during the treatment period were considered to be non-adherent and patients lost to follow-up at any time during follow-up were considered to have returned to smoking. Despite this limitation, the loss-to-follow-up is non-differential across treatment groups 
and much lower than in most smoking cessation trials. ${ }^{6-8}$ Third, our sample size was insufficient to provide meaningful estimates of the interaction between adherence to cessation treatment and smoking abstinence. Consequently, while we were able to examine treatment effects within each subgroup, we were unable to conclusively determine if treatment effects differ by adherence group. Finally, because the inclusion criteria included being motivated to quit, generalizability of the findings to all post-MI patients attempting to quit may be limited.

\section{CONCLUSION}

Adherence to study medication, regardless of assigned treatment, is associated with increased abstinence. Among patients who are partially adherent, there is some evidence of a benefit of bupropion for smoking cessation. The observed overall lack of effectiveness of bupropion for smoking cessation post-MI appears to be driven, at least in part, by a higher than expected prevalence of abstinence among patients who were adherent to placebo. Moreover, adherence to treatment may be a marker for motivation to quit smoking, with some patients being sufficiently motivated to quit without the use of bupropion and others deriving some benefit from its use. 


\section{ACKNOWLEDGEMENTS}

Authors Contributions: Dr. Filion had full access to all the data in the study and takes responsibility for the integrity of the data and the accuracy of the data analysis. Mrs. Grandi was responsible for interpretation and drafting of the manuscript. All other authors contributed equally to the interpretation of data and critical revision of the manuscript.

Conflicts of Interest: Dr. Eisenberg received funding from Pfizer Canada Inc. to perform the Evaluation of Varenicline (Champix ${ }^{\mathrm{TM}}$ ) in Smoking Cessation for Patients Post-Acute Coronary Syndrome (EVITA) Trial (ClinicalTrials.gov Identifier: NCT00794573). Mrs. Grandi and Drs. Joseph, O'Loughlin, Paradis, and Filion have no conflicts of interest to disclose.

Funding/Support: The Zyban as an Effective Smoking Cessation Aid for Patients Following an Acute Coronary Syndrome (ZESCA) Trial (NCT 00689611) was funded by the Canadian Institutes of Health Research (CIHR; grant number NCT64989) and the Heart and Stroke Foundation of Quebec. Mrs. Grandi is supported by a Frederick Banting and Charles Best Doctoral Award from the CIHR. Dr. Filion holds a CIHR New Investigator award. Dr. O’Loughlin holds a Canada Research Chair in the Early Determinants of Adult Chronic Disease.

Additional Contributions: The authors would like to thank Mr. Patrick Bélisle (McGill University Health Centre) for the analysis of the data. 


\section{REFERENCES}

1. Wilson K, Gibson N, Willan A, Cook D. Effect of smoking cessation on mortality after myocardial infarction: meta-analysis of cohort studies. Arch Intern Med 2000;160:939-44.

2. Critchley JA, Capewell S. Mortality risk reduction associated with smoking cessation in patients with coronary heart disease: a systematic review. JAMA 2003;290:86-97.

3. Rigotti NA, Munafo MR, Stead LF. Smoking cessation interventions for hospitalized smokers: a systematic review. Arch Intern Med 2008;168:1950-60.

4. Eisenberg MJ, Filion KB, Yavin D, et al. Pharmacotherapies for smoking cessation: a metaanalysis of randomized controlled trials. CMAJ 2008;179:135-44.

5. Eisenberg MJ, Blum LM, Filion KB, et al. The efficacy of smoking cessation therapies in cardiac patients: a meta-analysis of randomized controlled trials. Can J Cardiol 2010;26:73-9.

6. Tonstad S, Farsang C, Klaene G, et al. Bupropion SR for smoking cessation in smokers with cardiovascular disease: a multicentre, randomised study. Eur Heart J 2003;24:946-55.

7. Rigotti NA, Pipe AL, Benowitz NL, Arteaga C, Garza D, Tonstad S. Efficacy and safety of varenicline for smoking cessation in patients with cardiovascular disease: a randomized trial. Circulation 2010;121:221-9.

8. Rigotti NA, Thorndike AN, Regan S, et al. Bupropion for smokers hospitalized with acute cardiovascular disease. Am J Med 2006;119:1080-7.

9. Planer D, Lev I, Elitzur Y, et al. Bupropion for smoking cessation in patients with acute coronary syndrome. Arch Intern Med 2011;171:1055-60.

10. Eisenberg MJ, Grandi, S.M., Gervais, A, Joseph, L, O'Loughlin, J, Paradis, G, Rinfret, S, Sarrafzadegan, N, Sharma, S, Lauzon, C, Yadav, R, and Pilote, L, for the ZESCA Investigators. Bupropion for Smoking Cessation in Patients Hospitalized with Acute Myocardial Infarction: A Randomized, Placebo-Controlled Trial. JACC 2012;In Press.

11. Fish LJ, Peterson BL, Namenek Brouwer RJ, et al. Adherence to nicotine replacement therapy among pregnant smokers. Nicotine Tob Res 2009;11:514-8.

12. Shiffman S, Sweeney CT, Ferguson SG, Sembower MA, Gitchell JG. Relationship between adherence to daily nicotine patch use and treatment efficacy: secondary analysis of a 10-week randomized, double-blind, placebo-controlled clinical trial simulating over-the-counter use in adult smokers. Clin Ther 2008;30:1852-8. 
13. Shah ND, Dunlay SM, Ting HH, et al. Long-term medication adherence after myocardial infarction: experience of a community. Am J Med 2009;122:961 e7-13.

14. Hays JT, Leischow SJ, Lawrence D, Lee TC. Adherence to treatment for tobacco dependence: association with smoking abstinence and predictors of adherence. Nicotine Tob Res 2010;12:574-81.

15. Balmford J, Borland R, Hammond D, Cummings KM. Adherence to and reasons for premature discontinuation from stop-smoking medications: data from the ITC Four-Country Survey. Nicotine Tob Res 2011;13:94-102.

16. Sud A, Kline-Rogers EM, Eagle KA, et al. Adherence to medications by patients after acute coronary syndromes. Ann Pharmacother 2005;39:1792-7.

17. Horne R, Weinman, J, Hankins, M. The beliefs about medicines questionnaire: the development and evaluation of a new method for assessing the cognitive representation of medication. Psychol Health 1999;14:1-24.

18. Pierce JP, Gilpin EA. Impact of over-the-counter sales on effectiveness of pharmaceutical aids for smoking cessation. JAMA 2002;288:1260-4.

19. Thorndike AN, Biener L, Rigotti NA. Effect on smoking cessation of switching nicotine replacement therapy to over-the-counter status. American Journal of Public Health 2002;92:437-42.

20. Buczkowski K, Marcinowicz L, Czachowski S, Piszczek E. Motivations toward smoking cessation, reasons for relapse, and modes of quitting: results from a qualitative study among former and current smokers. Patient Preference and Adherence 2014;8:1353-63.

21. Prochaska JO, DiClemente CC. Stages and processes of self-change of smoking: toward an integrative model of change. Journal of Consulting and Clinical Psychology 1983;51:390-5.

22. Hyland A, Rezaishiraz H, Giovino G, Bauer JE, Michael Cummings K. Over-the-counter availability of nicotine replacement therapy and smoking cessation. Nicotine Tob Res 2005;7:54755 .

23. Fiore MC JC, Baker TB, et al. Treating Tobacco Use and Dependence: 2008 Update. Clinical Practice Guideline. Rockville, MD. U.S. Department of Health and Human Services. Public Health Service. . 2008.

24. Agaku IT KB, Dube SR, EIS officer CDC: Current cigarette smoking among adults - United States, 2005-2012. . Morb Mortal Wkly Rep 2014;63(2):29-34.

25. Cahill K, Stevens S, Perera R, Lancaster T. Pharmacological interventions for smoking cessation: an overview and network meta-analysis. Cochrane Database Syst Rev 2013;5:CD009329.

26. Centers for Disease Control and Prevention (CDC): Cigarette smoking among adults-United States, 2007. MMWR Morb Mortal Wkly Rep 2008, 57(45):1221-1226. 
Table 1. Baseline Demographic, Smoking, and Clinical Characteristics of Patients by Level of Adherence in Each Treatment Group.

\begin{tabular}{|c|c|c|c|c|c|c|}
\hline & \multicolumn{3}{|c|}{ Bupropion } & \multicolumn{3}{|c|}{ Placebo } \\
\hline & $\begin{array}{c}\text { Fully } \\
\text { Adherent* } \\
(n=66)\end{array}$ & $\begin{array}{c}\text { Partially } \\
\text { Adherent* } \\
(n=76)\end{array}$ & $\begin{array}{c}\text { Non- } \\
\text { Adherent* } \\
(n=46)\end{array}$ & $\begin{array}{c}\text { Fully } \\
\text { Adherent* } \\
(n=90)\end{array}$ & $\begin{array}{c}\text { Partially } \\
\text { Adherent } * \\
(\mathbf{n}=73)\end{array}$ & $\begin{array}{c}\text { Non- } \\
\text { Adherent* } \\
(\mathbf{n}=37)\end{array}$ \\
\hline Male, $\%$ & 87.9 & 85.7 & 72.9 & 78.9 & 87.7 & 88.6 \\
\hline Age, mean (SD) & $53.6(10.3)$ & $54.0(10.0)$ & $56.6(10.9)$ & $54.0(11.3)$ & $52.6(10.4)$ & $53.3(7.1)$ \\
\hline No. years smoked, mean (SD) & $32.8(12.4)$ & $31.8(12.7)$ & $35.9(14.0)$ & $33.1(13.0)$ & $32.1(11.7)$ & $32.3(9.6)$ \\
\hline No. cigs/day, mean (SD) & $22.5(10.4)$ & $23.9(10.5)$ & $23.1(12.0)$ & $23.0(9.8)$ & $23.7(11.5)$ & $22.5(9.9)$ \\
\hline Other smokers at home, $\%$ & 25.8 & 34.2 & 42.6 & 41.1 & 37.0 & 34.3 \\
\hline $\begin{array}{l}\text { No. of previous quit attempts, } \\
\text { mean (SD) }\end{array}$ & $2.3(6.1)$ & $2.4(6.0)$ & $1.8(2.7)$ & $2.4(3.1)$ & $1.8(2.7)$ & $2.1(2.6)$ \\
\hline $\begin{array}{l}\text { FTQ Nicotine dependence, } \\
\text { mean }(\mathrm{SD}) \dagger\end{array}$ & $5.3(2.3)$ & $5.5(2.2)$ & $5.7(2.3)$ & $5.6(2.1)$ & $5.7(2.2)$ & $5.8(2.2)$ \\
\hline $\begin{array}{l}\text { Beck Depression Inventory II } \\
\text { Score } \geq 14, \% \ddagger\end{array}$ & 13.6 & 24.7 & 21.3 & 15.6 & 26.0 & 20.0 \\
\hline Hyperlipidemia, \% & 54.6 & 54.6 & 42.6 & 48.9 & 46.6 & 45.7 \\
\hline Hypertension, \% & 39.4 & 37.7 & 53.2 & 41.1 & 35.6 & 28.6 \\
\hline Diabetes mellitus, \% & 25.8 & 20.8 & 21.3 & 6.7 & 16.4 & 14.3 \\
\hline Prior MI, \% & 21.2 & 16.9 & 21.3 & 20.0 & 23.3 & 25.7 \\
\hline Prior revascularization, $\%$ & 12.1 & 14.3 & 12.8 & 13.3 & 9.6 & 8.6 \\
\hline STEMI, \% & 72.7 & 58.4 & 57.5 & 66.7 & 64.4 & 71.4 \\
\hline PCI, \% & 57.6 & 40.3 & 48.9 & 58.9 & 42.5 & 54.3 \\
\hline $\mathrm{CABG}, \%$ & 4.6 & 3.9 & 8.5 & 6.7 & 8.2 & 8.6 \\
\hline \multicolumn{7}{|c|}{$\begin{array}{l}\text { Abbreviations: } \mathrm{SD}=\mathrm{Standard} \text { Deviation; } \mathrm{FTQ}=\text { Fagerstrom Tolerance Questionnaire; MI= Myocardial Infarction; STEMI= ST-Segment Elevation } \\
\text { Myocardial Infarction; } \mathrm{PCI}=\text { Percutaneous Coronary Intervention; } \mathrm{CABG}=\text { Coronary Artery Bypass Graft Surgery. *Adherence was defined as } \\
\text { follows, 1) fully adherent: a score of } 8 ; 2 \text { ) partially adherent: a score of } 4-7 \text {; and } 3 \text { ) non-adherent: a score of } \leq 3 \text {. } \dagger \text { Score ranges from } 0-63 \text {. } \$ \text { A score of } \\
\geq 14 \text { is indicative of depressive symptomatology. }\end{array}$} \\
\hline
\end{tabular}


Table 2. Side Effects by Level of Adherence in Each Treatment Group.

\begin{tabular}{|c|c|c|c|c|c|c|}
\hline & \multicolumn{3}{|c|}{ Bupropion } & \multicolumn{3}{|c|}{ Placebo } \\
\hline & $\begin{array}{c}\text { Fully } \\
\text { Adherent* } \\
(\mathbf{n}=66)\end{array}$ & $\begin{array}{c}\text { Partially } \\
\text { Adherent* } \\
(n=76)\end{array}$ & $\begin{array}{l}\text { Non-Adherent* } \\
(n=46)\end{array}$ & $\begin{array}{c}\text { Fully } \\
\text { Adherent* } \\
(\mathbf{n}=90)\end{array}$ & $\begin{array}{c}\text { Partially } \\
\text { Adherent* } \\
(\mathbf{n}=73)\end{array}$ & $\begin{array}{l}\text { Non-Adherent }{ }^{*} \\
(\mathbf{n}=37)\end{array}$ \\
\hline Any side effect, $\%$ & 42.4 & 53.3 & 34.7 & 41.1 & 42.5 & 37.8 \\
\hline \multicolumn{7}{|l|}{ No. side effects, $\%$} \\
\hline 0 & 57.6 & 46.8 & 65.3 & 58.9 & 57.5 & 62.2 \\
\hline 1 & 24.2 & 23.4 & 20.4 & 21.1 & 19.2 & 21.6 \\
\hline 2 & 3.0 & 16.9 & - & 8.9 & 5.5 & 10.8 \\
\hline$\geq 3$ & 15.2 & 13.0 & 14.3 & 11.1 & 17.8 & 5.4 \\
\hline \multicolumn{7}{|l|}{ Side effects, $\%$} \\
\hline Insomnia & 13.6 & 26.0 & 26.5 & 17.8 & 20.6 & 13.5 \\
\hline Dry mouth & 13.6 & 16.9 & 6.1 & 7.8 & 12.3 & 5.4 \\
\hline Bad taste in mouth & 6.1 & 11.7 & 6.1 & 8.9 & 6.9 & - \\
\hline Constipation & 9.1 & 5.2 & 8.2 & 2.2 & 8.2 & 10.8 \\
\hline Nausea & 6.1 & 7.8 & 4.1 & 2.2 & 2.7 & - \\
\hline
\end{tabular}


Table 3. Prevalence of Biochemically-Validated Smoking Abstinence by Treatment Group.

\begin{tabular}{|c|c|c|c|c|c|c|}
\hline & & $\begin{array}{c}\text { Fully } \\
\text { Adherent* } * \%\end{array}$ & $\begin{array}{c}\text { Partially } \\
\text { Adherent*, \% }\end{array}$ & $\begin{array}{c}\text { Non-Adherent } \\
\%\end{array}$ & $\begin{array}{c}\text { Difference in } \\
\text { Abstinence (Fully } \\
\text { Adherent - Non- } \\
\text { Adherent), } \\
\text { \% [95\% CI] }\end{array}$ & $\begin{array}{c}\text { Difference in } \\
\text { Abstinence } \\
\text { (Partially Adherent - } \\
\text { Non-Adherent), } \\
\text { \% [95\% CI] }\end{array}$ \\
\hline \multirow[t]{3}{*}{4 weeks $\dagger$} & Bupropion & 77.3 & 56.6 & 19.6 & $57.7[42.4,73.0]$ & $37.0[21.0,53.0]$ \\
\hline & Placebo & 67.8 & 41.1 & 8.1 & $59.7[46.6,72.7]$ & $33.0[18.7,47.3]$ \\
\hline & $\begin{array}{l}\text { Difference (Bupropion- } \\
\text { Placebo) }[95 \% \mathrm{CI}]\end{array}$ & $9.5[-4.5,23.5]$ & $15.5[-0.4,31.3]$ & $11.5[-3.0,25.9]$ & -- & -- \\
\hline \multirow[t]{3}{*}{9 weeks $\dagger$} & Bupropion & 72.7 & 39.5 & 17.4 & $55.3[40.0,70.7]$ & $22.1[6.6,37.6]$ \\
\hline & Placebo & 63.3 & 29.2 & 5.6 & $57.8[45.3,70.2]$ & $23.6[10.7,36.5]$ \\
\hline & $\begin{array}{l}\text { Difference (Bupropion- } \\
\text { Placebo) }[95 \% \mathrm{CI}]\end{array}$ & $9.4[-5.3,24.0]$ & $10.3[-4.9,25.5]$ & $11.8[-1.4,25.1]$ & -- & -- \\
\hline \multirow[t]{3}{*}{6 Months $\dagger$} & Bupropion & 47.0 & 28.8 & 15.2 & $31.8[15.9,47.7]$ & $13.6[-1.1,28.2]$ \\
\hline & Placebo & 43.8 & 14.3 & 2.8 & $41.0[29.4,52.7]$ & $11.5[1.7,21.3]$ \\
\hline & $\begin{array}{l}\text { Difference (Bupropion- } \\
\text { Placebo) }[95 \% \mathrm{CI}]\end{array}$ & $3.2[-12.7,19.0]$ & $14.5[1.3,27.7]$ & $12.4[0.8,24.1]$ & -- & -- \\
\hline \multirow[t]{3}{*}{12 Months $\dagger$} & Bupropion & 40.0 & 23.3 & 13.3 & $26.7[11.2,42.2]$ & $10.0[-3.9,23.8]$ \\
\hline & Placebo & 39.8 & 10.0 & 2.8 & $37.0[25.5,48.5]$ & $7.2[-1.62,16.1]$ \\
\hline & $\begin{array}{l}\text { Difference (Bupropion- } \\
\text { Placebo) }[95 \% \mathrm{CI}]\end{array}$ & $0.2[-15.5,15.9]$ & $13.3[1.3,25.3]$ & $10.7[-0.7,21.9]$ & -- & -- \\
\hline
\end{tabular}

